\title{
SYSTEMIC FUNGAL INFECTIONS EMERGING INFECTION IN NEWBORN
}

\author{
Thakre R.*
}

\section{INTRODUCTION}

Fungal infections in general and Candida species in particular are increasingly being recognized to cause late onset sepsis ( $>3$ day) and compete with bacteria today as one of the leading causes of nosocomial infections ${ }^{1}$. Most fungal infections in neonates are due to Candida species; a much smaller number of infections may be attributed Malassezia, Zygomycetes, or Aspergillus pathogens. Candida produce infections that range from nonlife-threatening mucocutaneous illnesses to invasive processes that may involve virtually any organ system. Preterm infants and sick term infants in NICUs have a specific, increased risk for invasive fungal infection.

\section{INCIDENCE}

The cumulative incidence of invasive candidiasis is upto $5 \%$ of low-birth-weight babies and is inversely proportional to birth weight ${ }^{2}$. About $20 \%$ of babies weighing less than $1000 \mathrm{~g}$ develop invasive fungal infections. The overall mortality rate for disseminated fungal infections in this group of babies is very high, often approaching $50 \%{ }^{3}$. Candida colonization can be detected in approximately 30\% of infants weighing less than $1500 \mathrm{~g}$ birth weight. Colonization increases with decreasing birth weight ${ }^{4,5}$. Colonization is not an independent risk factor for subsequent candidiasis. Acquiring Candida does not always translate into systemic infection, but previous colonization is a required step before the occurrence of invasive candidiasis ${ }^{6}$. Nearly $80 \%$ of cases diagnosed in premature infants occur in the first 42 days of life ${ }^{7}$. In term newborns the incidence of candidemia is 10 fold less and is especially related to congenital anomalies especially of the gastrointestinal tract.

\section{CANDIDA SPECIES}

Candida organisms are saprophytic yeasts that are ubiquitous and are constituents of the normal microbial flora of humans. All Candida species form pseudohyphae that are important in invasion. Candida albicans is the predominant species associated with maternally acquired neonatal disease ${ }^{8}$. Candida parapsilosis is a common species in nosocomially acquired infection (central line infection), and other species such as Candida stellatoidea, Candida lusitania, Candida krusei, and Candida glabrata are reported less frequently ${ }^{9}$. Any Candida species may cause disease in neonates.

* Professor, Department of Pediatrics, MGM Hospital, Aurangabad, India

\section{For Correspondence}

Dr. Rhishikesh Thakre, D.M. (Neo), M.D., Professor,

Department of Pediatrics,

MGM Hospital, Aurangabad. 431001. MS

E-mail:rhishikesht@gmail.com 


\section{PATHOGENESIS}

Neonates may acquire Candida by vertical or nosocomial transmission (person to person contact or via infusates). In vertical transmission, acquisition may occur either during gestation or at the time of delivery. A combination of infecting dose and host factors play a role in the development of candidiasis. The organism produces multiple virulence factors such as adhesins, proteinases, and phospholipases that promote attachment and invasion. After penetration of epithelial or endothelial barriers, in this setting, Candida can penetrate into lymphatics, blood vessels, and deep tissues, resulting in disseminated infection. Disseminated candidiasis can cause disease in any organ system.

Table 1 : Risk factors for candidiasis

\begin{tabular}{|l|l|}
\hline Gestational age $<\mathbf{3 2}$ week & Umbilical catheters \\
\hline Birth weight $1500 \mathrm{~g}$ & $\begin{array}{l}\text { Peripheral or central } \\
\text { venous catheters }\end{array}$ \\
\hline Apgar score $<5$ at 5 minutes & Abdominal surgery \\
\hline Intubation/mechanical ventilation & Use of intralipid/TPN \\
\hline Prolonged administration of antibiotics & Corticosteroid use \\
\hline
\end{tabular}

The most important of these factors appears to be the number of prior antibiotics and the duration of therapy.

Risk factors for candida colonization and sepsis are similar

\section{CLINICALMANIFESTATIONS}

Clinical manifestations vary depending on the location and extent of the infection. The classic clinical picture of systemic candidiasis in neonates is indistinguishable from bacterial sepsis $^{2}$. Symptoms are often more subtle and indolent. Among these, respiratory dysfunction and apnea were the most common presenting signs in large series ${ }^{10}$. A significant proportion of neonates will present simultaneously with localized signs of candidal infection at one or more other sites. In addition to fungaemia, infants may present with pneumonia, meningitis, renal tract infection, ophthalmitis, osteomyelitis, endocarditis, liver abscesses, and skin abscesses ${ }^{11}$. Candida species. Always should be considered in the differential diagnosis of sepsis in the neonate, particularly late onset sepsis ${ }^{12}$. Up to $75 \%$ of cases of neonatal candidiasis present with infection of two or more organs.

\section{Table 2 : Clues to fungal infection}

Ashen grey skin complexion

- Indolent clinical course

- Persistently elevated C Reactive protein

- New-onset or persistent thrombocytopenia

- Sepsis with Negative blood culture

\section{DIAGNOSIS}

Documented invasive candidiasis is defined as a positive culture from normally sterile body fluid. No special medium is required for growth of Candida in the laboratory. The isolation of Candida from wounds, skin, urine, or stool specimens is not diagnostic of disease. On the other hand, growth of Candida spp. From sterile specimens (e.g., blood or CSF) is always diagnostic of infection. Candida species grow robustly in the routine blood culture media used in most clinical laboratories, and these media usually yield the organism within 48 to 72 hours of incubation. Widespread infection despite negative cultures is common ${ }^{13}$.

Overgrowth of bacteria on nonselective media can easily inhibit or hide the growth of fungi. Selective culture media can be made inhibitory to bacteria by maintaining a low $\mathrm{pH}$ (e.g., Sabouraud dextrose agar) or by including antibacterial agents in the media (e.g., gentamicin and chloramphenicol). To date PCR testing is not widely available for clinical use.

\section{Screening for disseminated disease}

Prolonged symptoms, persistent candidemia $(>5 \mathrm{~d})$, or laboratory evidence of end-organ damage should prompt investigation for disseminated disease ${ }^{14,15}$. Dissemination affects length of treatment. A thorough evaluation to rule out disseminated candidial infection in infants with this syndrome should be done routinely by:

- completing a microbiological evaluation of blood, urine, and CSF.

- Indirect opthalmoscopy evaluation of the retina

- an echocardiographic evaluation of the heart

- a renal ultrasound

\section{Consequences of missed or delayed diagnosis}

Delayed treatment results in increased rates of intraventricular hemorrhage, chronic lung disease, retinopathy of prematurity requiring surgical therapy, and up to a four fold increase in long-term neuro developmental delays ${ }^{16}$. The associated mortality with invasive candidiasis is three times higher than that of uninfected infants of similar gestational age and birth weight. Untreated, the mortality exceeds $80 \%$.

\section{TREATMENT}

\section{Empiric Treatment}

Some studies have reported use of empiric antifungals pending culture results while some have used clinical scores. These have not been studied in prospective controlled trials. There is lack of evidence for routine empiric treatment. In certain circumstances, empiric antifungal therapy for 48-72 hours may be warranted in infants with negative initial culture results who still have signs and symptoms of sepsis after 48 hours of antibacterial treatment and who are recultured ${ }^{17}$. In 
addition, the infants must have one of the following criteria:

- Thrombocytopenia $(<100 \times 109 / \mathrm{L})$

- Necrotising enterocolitis or focal bowel perforation

- Weight of less than $750 \mathrm{~g}$ or a gestational age of less than 26 weeks

\section{Definitive treatment ${ }^{18}$}

Isolation of candida from sterile site warrants definitive therapy. Amphotericin B is the drug of choice for invasive fungal infections. It is effective against most Candida species causing disease in neonates except for $\mathrm{C}$ lusitaniae Test doses are not required because the drug is better tolerated in neonates than in adults. Age and underlying disease are not associated with increased risk of nephrotoxicity. Lipid formulations of amphotericin B are very much expensive and do not appear to be more efficacious than conventional amphotericin B deoxycholate, and their use should be limited to patients who are either refractory to, or intolerant of, the regular amphotericin B preparation Flucytosine is not recommended as monotherapy because resistance develops rapidly, but the antifungal is given occasionally in combination with amphotericin B for central nervous system infections. The lack of a parenteral formulation limits the utility of flucytosine. Fluconazole is both safe and effective for invasive fungal infections. $50 \%$ of C glabrata and $100 \%$ of C krusei isolates have been reported to be resistant to fluconazole. Breakthrough (or persistence of) candidemia in the face of ongoing antifungal therapy suggests the possibility of an infected intravascular device, significant immunosuppression, or microbiological resistance.

Table 3 : Antifungal Agents

\begin{tabular}{|c|c|c|c|}
\hline DRUG & DOSE & Toxicity & Comments \\
\hline Amphotericin B & $\begin{array}{l}1 \\
\mathrm{mg} / \mathrm{kg} / \mathrm{d} \\
\mathrm{q} 24 \mathrm{~h} \mathrm{IV}\end{array}$ & $\begin{array}{l}\text { Anemia, hypokalemia, } \\
\text { nephrotoxicity }\end{array}$ & $\begin{array}{l}\text { Monitor blood urea nitrogen, } \\
\text { creatinine, and } \mathrm{K}+\text { daily initially } \\
\text { and twice weekly if stable after } \\
1 \mathrm{week} \text {; hold dose until } \mathrm{K}+<3 \\
\mathrm{mEq} / \mathrm{dL} \text { is corrected. Give } \\
\text { infusion over } 2-4 \mathrm{~h} \text {. }\end{array}$ \\
\hline $\begin{array}{l}\text { Lipid } \\
\text { formulations of } \\
\text { amphotericin B }\end{array}$ & $\begin{array}{l}3-7 \\
\mathrm{mg} / \mathrm{kg} / \mathrm{d} \\
\mathrm{q} 24 \mathrm{~h} \mathrm{IV}\end{array}$ & $\begin{array}{l}\text { Less nephrotoxic than } \\
\text { amphotericin B }\end{array}$ & $\begin{array}{l}\text { Monitor renal function and } \mathrm{K}+ \\
\text { as above }\end{array}$ \\
\hline Flucytosine & $\begin{array}{l}50-150 \\
\mathrm{mg} / \mathrm{kg} / \mathrm{d} \\
\mathrm{q} 6 \mathrm{~h} \mathrm{PO}\end{array}$ & $\begin{array}{l}\text { Bone marrow } \\
\text { suppression, } \\
\text { hepatotoxicity, and } \\
\text { gastrointestinal } \\
\text { symptoms }\end{array}$ & $\begin{array}{l}\text { Good penetration into CSF; } \\
\text { must reduce dosage in patients } \\
\text { with renal failure }\end{array}$ \\
\hline Fluconazole & $\begin{array}{l}3-6 \\
\mathrm{mg} / \mathrm{kg} / \mathrm{d} \\
\mathrm{q} 24 \mathrm{~h} \\
\mathrm{PO}, \mathrm{IV}\end{array}$ & $\begin{array}{l}\text { Good penetration into } \\
\text { CSF }\end{array}$ & $\begin{array}{l}\text { Drug interaction with } \\
\text { cytochrome P-450 system }\end{array}$ \\
\hline Itraconazole & $\begin{array}{l}5 \\
\mathrm{mg} / \mathrm{kg} / \mathrm{d} \\
\mathrm{q} 24 \mathrm{~h} \\
\text { PO }\end{array}$ & & Limited experience \\
\hline
\end{tabular}

Additionally, caspofungin an echinocandin, and voriconazole and posaconazole the newest azole agents, are promising future treatment options due to their excellent broad-spectrum activity against Candida species. Published data on the use of these medications in infants are limited.

\section{Duration of treatment}

In the absence of deep tissue involvement or abscess formation, treatment usually is continued 5 to 7 days after clinical improvement. At least 14 days of therapy after the last positive blood-culture result is recommended for neonates with candidemia in the absence of disseminated disease. Prolonged antifungal therapy (i.e. 6 weeks) is frequently required for chronic disseminated candidiasis, endocarditis, endophthalmitis, and osteomyelitis.

\section{Monitoring lab parameters during treatment}

- Liver and renal function should be evaluated at the time of diagnosis (or if candidemia is persistent) because they may suggest liver or renal dissemination and the need for ultrasonography.

- Antifungal treatment can affect serum electrolytes and the hematologic, hepatic, and renal systems and should be monitored during treatment.

- In patients with persistent candidemia of longer than 5 days, repeat screening tests for vegetation or abscess

- Persistent thrombocytopenia may indicate therapeutic failure.

\section{Anti fungal Prophylaxis}

There is insufficient evidence to support the use of prophylactic oral antifungal agents in very low birth weight infants in the neonatal intensive care unit. ${ }^{19}$ Prophylaxis with intravenous fluconazole in VLBW/ELBW infants showed significant reduction in invasive fungal infections. This finding should be interpreted cautiously. ${ }^{20}$ For some NICUs with high rate of infection, and those with large populations of $<1000$ gram infants, prophylaxis may be appropriate. One concern with fluconazole prophylaxis is the potential for the emergence of resistance over time, and this issue is under further study. Further trials are needed to provide more precise estimates of effect size, and to assess the effect on mortality, neurodevelopment, and the emergence of antifungal resistance. $^{21,22}$

Malassezia furfur ${ }^{17}$, a lipid dependent fungus, is another cause of systemic fungemia in neonates. It frequently involves babies receiving intralipid through a central venous catheter. Lung lesions, pulmonary vasculitis, septic thrombi are the chief affections and involvement of other organ systems is uncommon. Although Amphotericin B has been used in these cases, they usually resolve on removal of indwelling central catheters and omitting intralipid. 
Aspergillosis ${ }^{17}$ contamination through the ventilation system is one of the predisposing factors. One presentation involves injured skin areas that rapidly (over $24 \mathrm{~h}$ ) progress to necrotic eschars. Diagnosis is made by demonstrating septate hyphae with $45^{\circ}$ angles characteristic of Aspergillus species.

\section{Table 4 : Good practices to reduce fungal infections}

- Increased compliance with hand hygiene standards

- Improved accuracy of the diagnosis of bacteremia

- Reduced line and line connection (hub) bacterial contamination

- Maximal barrier precautions for central line placement

- Improve nursing practices to maintain skin integrity. Avoid skin abrasions.

- Decreased number of skin punctures

- Decreased duration of IV lipid infusion

- Decreased duration of central venous line use

- Early enteral nutrition preferably by breast milk.

- Remove a central venous catheter on suspicion of severe fungal infection or within 24 hours of a positive culture for fungus

- Avoid use of antacids as gastric pH favors fungal colonization.

- Use narrowest spectrum antibiotics possible

- Reduce duration of antibiotics. Stop antibiotics if cultures negative.

- Use HEPA filtration ventilation systems and take measures for containment of dust, especially during hospital renovation and construction

\section{REFERENCES}

1. Benjamin DK, Jr Charles Poole, Steinbach WJ, Rowen JL Walsh TJ. Neonatal Candidemia and End-Organ Damage: A Critical Appraisal of the Literature Using Meta-analytic Techniques. Pediatrics 2003;112;634-640

2. Baley JE, Kliegman TM and Fanaroff AA, 1984. Disseminated fungal infections in very low-birth eight infants: clinical manifestations and epidemiology. Pediatrics. 72:144-152.

3. Stoll BJ, Gordon T, Korones SB, Shankaran S, Tyson JE, Bauer CR, Fanaroff AA, Lemons JA, Donovan EF, Oh W, Stevenson DK, Ehrenkranz RA, Papile LA, Verter J, Wright LL 1996. Late-onset sepsis in very low birth weight neonates: a report from the National Institute of Child Health and Human Development Neonatal Research Network. J Pediatr. 129:6371 .

4. Huang YC, Li CC, Liu TY, Lien RI, Chou YH, Wu JL, et al Association of fungal colonization and invasive disease in very low birth weight infants. Paediatr Infect Dis Jr 1992;17:819-22.
5. Sharp AM, Odds FC, Evans EG 1992. Candida strains from neonates in a special care baby unit. Arch Dis Child. 67:48-52.

6. Saiman L, Ludington E, Pfaller M. Risk factors for candidemia in neonatal intensive care unit patients. The National Epidemiology of Mycosis Survey study group. Pediatr Infect Dis J(2000) 19: pp 319-24.

7. Benjamin DK, Jr Stoll BJ, Fanaroff AA. Neonatal candidiasis among extremely low birth weight infants: risk factors, mortality, and neurodevelopmental outcomes at 1822 months. Pediatrics (2005)

8. Reef SE, Lasker BA, Butcher DS, McNeil MM, Pruitt R, Keyserling H, Jarvis WR. 1998. Nonperinatal nosocomial transmission of Candida albicans in a neonatal intensive care unit: Prospective study. JClin Microbiol. 36:1255-1259.

9. Finkelstein R, Reinhertz G, Hashman N, Merzbach D. 1993 Outbreak of Candida tropicalis fungemia in a neonatal intensive care unit. Infect Control Hosp Epidemiol. 14:587-90.

10. Anker VD JN, Popele NMV, Sauer PJ. 1995. Antifungal agents in neonatal systemic candidiasis. Antimicrob. Agents Chemother. 39:1391-1397.

11. Benjamin DK Jr, Kelly Ross, Ross E McKinney, Benjamin DK, Auten R, Fisher RG. When To Suspect Fungal Infection In Neonates: A Clinical Comparison Of Candida Albicans and Candida Parapsilosis Fungemia With Coagulse-Negative Staphylococcal Bacteremia. Paediatrics 2000;106:712-18.

12. Cordero L, Sananes M, Ayers LW. 1999. Bloodstream infections in a neonatal intensive-care unit: 12 years' experience with an antibiotic control program. Infect Control Hosp Epidemiol. $20: 242-46$

13. Johnson DE, ThompsonTR, Green TP, Ferrieri P. 1984 Systemic candidiasis in very low-birth-weight infants (less than 1,500 grams). Pediatrics. 73:138-43.

14. Chapman RL, Faix RG. Persistently positive cultures and outcome in invasive neonatal candidiasis. Pediatr Infect Dis $J$ 2000 Sep; 19(9): 822-7

15. Noyola DE, Fernandez M, Moylett EH, Baker CJ. Ophthalmologic, visceral, and cardiac involvement in neonates with candidemia. Clin Infect Dis 2001 Apr 1; 32(7): 1018-23

16. Stoll BJ, Hansen NI, Adams-Chapman I, et al. Neurodevelopmental and growth impairment among extremely low-birth-weight infants with neonatal infection. JAMA 2004 Nov 17; 292(19): 2357-65

17. Kaufman D. Fungal Infections in Preterm Infants. http://www.emedicine.com/ped/topic3085.htm.

18. Blyth CC, Palasanthiran P, O'Brien TA. Antifungal Therapy in Children With Invasive Fungal Infections: A Systematic Review. Pediatrics 2007;119;772-784. 
19. Austin NC, Darlow B. Prophylactic oral antifungal agents to prevent systemic candida infection in preterm infants. Cochrane Database ofSystematic Reviews 2003, Issue 4.

20. Clerihew L, Austin N, McGuire W. Prophylactic systemic antifungal agents to prevent mortality and morbidity in very low birth weight infants Cochrane Database of Systematic Reviews 2007, Issue 4.
21. Long SS, Stevenson DK. Reducing Candida infections during neonatal intensive care: management choices, infection control, and fluconazole prophylaxis. J Pediatr 2005 Aug. 147(2): 135-41

22. Fanaroff AA. Fluconazole for the prevention of fungal infections: get ready, get set, caution. Pediatrics 2006 Jan; $117(1): 214-15$ 